A T TA CH M I CA SCANDINA I CA 3 (1949) $660-676$

\title{
The Crystal Structure of the Isomorphous Orthoborates of \\ Cobalt and Magnesium
}

\author{
SVEN V. BERGER \\ Institute of Chemistry, University of Uppsala, Uppsala, Sweden
}

\begin{abstract}
Crystals of orthoborates of cobalt and magnesium have been described by Ebelmen ${ }^{1}$, Mallard ${ }^{2}$, le Chatelier ${ }^{3}$, Ouvrard ${ }^{4}$, Guertler ${ }^{5}$ and HofmannHoschele ${ }^{6}$ among others. They are reported to be isomorphous and orthorhombic with a rather perfect cleavage parallel to (110). Those of $\mathrm{Mg}_{3}\left(\mathrm{BO}_{3}\right)_{2}$ are further described to have the axial ratios $0.641: 1: 0.549$ and to be insoluble in dilute acetic acid.

The crystals used in the present investigation were prepared by melting together in a $\mathrm{ZrO}_{2}$-crucible $3 \mathrm{CoO}(3 \mathrm{MgO})$ with $1 \mathrm{~B}_{2} \mathrm{O}_{3}$. They form thin needles parallel to the axis, which was chosen as $c$-axis. By means of crystals picked out, the crystallographic information given above could be confirmed. Of each substance one needle, suitable for taking single crystal photographs, was examined by the rotation and Weissenberg methods, and the ground crystals by the powder method. Mo-K-radiation was used for the single crystal and $\mathrm{Cr}$-K-radiation for the powder exposures. The parameters of the atoms were determined by Fourier-methods ?
\end{abstract}

\section{THE UNIT CELL AND THE SPACE GROUP}

The Laue-symmetry is $D_{2 h}$-mmm. Rotation and Weissenberg photographs were taken about the $b$ and $c$ (needle) directions. In the first case only the 0-layer line was registered. By rotation around the needle axis, layer lines with $l=0-6$ were obtained. The dimensions of the unit cell were determined by means of powder photographs from a focusing camera. A list of the observed diffraction lines is given in the Table 1. 
Table 1. Powder diffraction data for the orthorhombic borates of cobalt and magnesium.

\begin{tabular}{|c|c|c|c|c|c|c|c|}
\hline \multicolumn{5}{|c|}{$\mathrm{Co}_{3}\left(\mathrm{BO}_{3}\right)_{2}$} & \multicolumn{3}{|c|}{$\mathrm{Mg}_{3}\left(\mathrm{BO}_{3}\right)_{2}$} \\
\hline$h k l$ & & Int. & $\sin ^{2} \Theta_{\text {obs }}$ & $\sin ^{2} \theta_{\text {calc }}$ & Int. & $\sin ^{2} \Theta_{\text {obs }}$ & $\sin ^{2} \Theta_{\text {calc }}$ \\
\hline 020 & $\alpha$ & $\mathbf{w}-$ & 0.0719 & 0.0736 & $\mathbf{w}$ & 0.0731 & 0.0740 \\
\hline 011 & $a$ & $\mathbf{w}-$ & .0803 & .0823 & $\mathbf{w}-$ & .0817 & .0829 \\
\hline 101 & $a$ & $w$ & .1076 & .1078 & $\mathbf{s}$ & .1088 & .1097 \\
\hline 111 & $a$ & vw & .1255 & .1263 & $\mathrm{~m}$ & .1273 & .1283 \\
\hline 121 & $\alpha$ & $\mathbf{8}$ & .1814 & .1815 & vs & .1839 & .1838 \\
\hline 130 & $a$ & $\mathbf{m}$ & .2094 & .2096 & $\mathbf{m}$ & .2113 & .2114 \\
\hline 031 & $a$ & $\mathbf{w}$ & .2299 & .2296 & $\mathrm{~m}-$ & .2296 & .2310 \\
\hline 201 & $a$ & $\mathbf{m}$ & .2402 & .2397 & $\mathbf{s}$ & .2454 & .2449 \\
\hline 220 & $\alpha$ & $w+$ & .2498 & .2495 & $\mathrm{~m}-$ & .2544 & .2540 \\
\hline 211 & $a$ & $\mathbf{s}$ & .2588 & .2581 & vs & .2633 & .2633 \\
\hline 131 & $a$ & $\mathbf{m}$ & .2739 & .2736 & vs & .2762 & .2762 \\
\hline 102 & $a$ & $w+$ & .2999 & .2995 & $\mathbf{m}-$ & .3039 & .3041 \\
\hline 221 & $\alpha$ & $w-$ & .3139 & .3133 & $\mathbf{w}-$ & .3191 & .3189 \\
\hline 112 & $a$ & $\mathbf{w}-$ & .3189 & .3181 & $\mathbf{w}-$ & .3228 & .3225 \\
\hline 022 & $a$ & $\mathbf{w}-$ & .3298 & .3292 & $\mathbf{w}-$ & .3328 & .3330 \\
\hline 141 & $a$ & $\mathbf{w}$ & .4024 & .4024 & $\mathbf{w}$ & .4059 & .4058 \\
\hline 231 & $a$ & $\mathbf{w}$ & .4056 & .4053 & vw & .4112 & .4112 \\
\hline 202 & $a$ & $\mathbf{s}$ & .4317 & .4311 & vs & .4389 & .4390 \\
\hline 132 & $a$ & $\mathbf{s}$ & .4656 & .4654 & vs & .4710 & .4707 \\
\hline 311 & $\alpha$ & vw & .4776 & .4775 & $\mathbf{w}-$ & .4884 & .4881 \\
\hline 150 & $a$ & $\mathbf{w}-$ & .5044 & .5042 & $\mathbf{w}-$ & .5075 & .5075 \\
\hline 051 & $a_{1}$ & $\mathbf{m}$ & .5248 & .5242 & $w+$ & .5270 & .5272 \\
\hline & $\alpha_{2}$ & vw & .5264 & .5260 & $\mathbf{v w}$ & .5286 & .5289 \\
\hline 321 & $a_{1}$ & $\mathbf{s}$ & .5330 & .5330 & $\mathbf{m}$ & .5436 & .5436 \\
\hline & $a_{2}$ & $\mathbf{w}$ & .5347 & .5345 & $\mathbf{w}$ & .5451 & .5454 \\
\hline 042 & $\alpha_{1}$ & $\mathbf{w}-$ & .5500 & .5500 & $\mathbf{w}$ & .5549 & .5550 \\
\hline & $a_{2}$ & & & & vw & .5562 & .5567 \\
\hline 330 & $\alpha_{1}$ & $\mathbf{s}$ & .5608 & .5608 & vs & .5713 & .5713 \\
\hline & $a_{2}$ & $\mathbf{m}$ & .5627 & .5626 & $\mathbf{m}+$ & .5733 & .5732 \\
\hline 013 & $\alpha_{1}$ & $\mathbf{m}-$ & .5935 & .5932 & $\mathbf{m}$ & .6002 & .6009 \\
\hline & $a_{2}$ & $\mathbf{w}-$ & .5955 & .5952 & $\mathbf{w}$ & .6024 & .6028 \\
\hline 331 & $a_{1}$ & $\mathbf{v w}$ & .6248 & .6248 & $\mathbf{w}-$ & .6362 & .6360 \\
\hline & $a_{2}$ & & & & vw & .6386 & .6382 \\
\hline 302 & $a_{1}$ & $\mathbf{w}$ & .6510 & .6508 & $\mathbf{v w}$ & .6636 & .6638 \\
\hline 060 & $\alpha_{1}$ & $\mathbf{m}-$ & .6622 & .6622 & $\mathbf{m}$ & .6661 & .6660 \\
\hline & $a_{2}$ & $\mathbf{w}$ & .6645 & .6647 & $\mathbf{w}$ & .6684 & .6683 \\
\hline 123 & $a_{1}$ & $\mathbf{s}$ & .6922 & .6923 & $\mathbf{s}-$ & .7012 & .7019 \\
\hline & $a_{2}$ & $\mathbf{m}$ & .6946 & .6948 & $\mathbf{m}-$ & .7035 & .7039 \\
\hline 251 & $a_{1}$ & $\mathbf{s}$ & .6996 & .6999 & $\mathbf{8}$ & .7070 & .7070 \\
\hline & $\alpha_{2}$ & $\mathbf{m}$ & .7024 & .7023 & $\mathbf{m}$ & .7096 & .7094 \\
\hline 400 & $\alpha_{1}$ & $\mathbf{m}-$ & .7024 & .7025 & m & .7196 & .7193 \\
\hline & $\alpha_{2}$ & $w+$ & .7050 & .7051 & $\mathbf{w}$ & .7220 & .7220 \\
\hline
\end{tabular}




\begin{tabular}{|c|c|c|c|c|c|c|}
\hline \multicolumn{4}{|c|}{$\mathrm{Co}_{3}\left(\mathrm{BO}_{3}\right)_{2}$} & \multicolumn{3}{|c|}{$\mathrm{Mg}_{3}\left(\mathrm{BO}_{3}\right)_{2}$} \\
\hline$h k l$ & Int. & $\sin ^{2} \Theta_{\text {obs }}$ & $\sin ^{2} \Theta_{\text {calc }}$ & Int. & $\sin ^{2} \Theta_{\text {obs }}$ & $\sin ^{2} \theta_{\text {calc }}$ \\
\hline \multirow{2}{*}{033} & $\mathbf{w}$ & 0.7400 & 0.7403 & $\mathbf{w}$ & 0.7492 & 0.7498 \\
\hline & vw & .7435 & .7432 & vw & .7520 & .7521 \\
\hline \multirow{2}{*}{203} & $a_{1}$ & & & $w-$ & .7619 & .7627 \\
\hline & $\alpha_{2}$ & & & vw & .7655 & .7656 \\
\hline \multirow{2}{*}{401} & $\mathbf{w}+$ & .7674 & .7665 & $\mathbf{m}$ & .7846 & .7846 \\
\hline & vw & .7700 & .7692 & $\mathbf{w}$ & .7869 & .7870 \\
\hline \multirow{2}{*}{420} & $a_{1}$ & & & $\mathbf{m}$ & .7935 & .7937 \\
\hline & $\alpha_{2}$ & & & $w$ & .7958 & .7961 \\
\hline \multirow{2}{*}{411} & $\mathbf{m}$ & .7850 & .7848 & $\mathbf{m}$ & .8032 & .8031 \\
\hline & $\mathbf{w}$ & .7857 & .7878 & $\mathbf{w}$ & .8060 & .8059 \\
\hline \multirow{2}{*}{332} & $\mathrm{~m}$ & .8161 & .8162 & $w+$ & .8300 & .8302 \\
\hline & $\mathrm{w}$ & .8189 & .8190 & $v w$ & .8330 & .8332 \\
\hline \multirow{2}{*}{$\begin{array}{l}260 \\
421\end{array}$} & $\mathbf{w}-$ & .8380 & .8382 & vw & .8465 & .8461 \\
\hline & $a_{1}$ & & & vw & .8578 & .8580 \\
\hline 350 & $a_{1}$ & & & vw & .8647 & .8648 \\
\hline \multirow{3}{*}{$\begin{array}{l}261 \\
143\end{array}$} & $\mathbf{w}-$ & .9041 & .9021 & vw & .9104 & .9104 \\
\hline & $\mathbf{w}-$ & .9131 & .9133 & $\mathbf{w}$ & .9238 & .9241 \\
\hline & $a_{2}$ & & & vw & .9274 & .9272 \\
\hline \multirow{3}{*}{$\begin{array}{l}233 \\
062\end{array}$} & vw & .9157 & .9159 & $v w$ & .9288 & .9291 \\
\hline & $\mathbf{w}+$ & .9178 & .9180 & & & \\
\hline & vw & .9208 & .9210 & & & \\
\hline \multirow[t]{2}{*}{431} & $\mathbf{m}-$ & .9319 & .9322 & & & \\
\hline & $w-$ & .9352 & .9356 & & & \\
\hline \multirow{3}{*}{$\begin{array}{l}170 \\
402\end{array}$} & $a_{1}$ & & & vw & .9513 & .9512 \\
\hline & $\mathbf{m}$ & .9580 & .9582 & $\mathbf{w}$ & .9781 & .9784 \\
\hline & $\mathbf{w}-$ & .9615 & .9618 & vw & .9815 & .9819 \\
\hline
\end{tabular}

Measurements in the reflection region of the highest $\sin ^{2} \Theta$ led to the following axial lengths (referred to wave lengths of $\mathrm{Cr}-\mathrm{K} \alpha_{1}=2.28962 \AA$ and $\mathrm{Cr}-\mathrm{K} \alpha_{2}=2.29352 \AA$ )

\begin{tabular}{llc}
\hline & $\mathrm{Co}_{3}\left(\mathrm{BO}_{3}\right)_{2}$ & $\mathrm{Mg}_{3}\left(\mathrm{BO}_{3}\right)_{2}$ \\
\hline & & \\
$a$ & $5.462 \pm 0.002 \AA$ & $5.398 \pm 0.002 \AA$ \\
$b$ & $8.436 \pm 0.002$ & $8.416 \pm 0.002$ \\
$c$ & $4.529 \pm 0.002$ & $4.497 \pm 0.002$
\end{tabular}

The values given above correspond to the axial ratios - values for the Mgcompound within parentheses $-0.648: 1: 0.537(0.642: 1: 0.535)$. The unit 
cell containing $2 \mathrm{Me}_{3}\left(\mathrm{BO}_{3}\right)_{2}$ has the volume $208.7(204.3) \AA^{3}$, and the calculated density is $4.69(3.10) \mathrm{g} \cdot \mathrm{cm}^{-3}$. The observed densities are $4.66(3.04) \mathrm{g} \cdot \mathrm{cm}^{-3}$.

The observed powder and Weissenberg reflections correspond to a simple orthorhombic translation lattice since general planes $h k l$ show no regular absences. However, planes $h k 0$ and $0 k l$ reflect only if $h+k$ and $k+l$ are even. These conditions, and the fact that no piezoelectric effect could be detected, led to $D_{2 h}^{12}-P n m n$ as the most probable space group.

\section{INTENSITY MEASUREMENTS}

For Mo-K-radiation the observed intensities are based on the relation $I_{\beta}: I_{\alpha 2}: I_{\alpha 1}=1: 2: 4$ for a given reflection and the relative $/ F /$-values are determined according to

$$
I=C \cdot \lambda^{3} \cdot \frac{1+\cos ^{2} 2 \Theta}{\cos ^{2} \mu \cdot \sin v} \cdot / \mathrm{F} /^{2}
$$

where $\mu=$ the angle between the primary beam and the equatorial plane, and

$v=$ the azimute of the reflection from the plane through the primary beam and the rotation axis.

In the present case, where crystals containing light atoms were exposed with Mo-K-radiation, no corrections for absorption are performed. The graphs given by $\mathrm{Lu}^{8}$ for the inversed value of $\frac{1+\cos ^{2} 2 \Theta}{\cos ^{2} \mu \cdot \sin v}$ have been used.

The Weissenberg photographs were taken with the equi-inclination method. The connection between intensities of reflections from different layer lines was obtained by changing rotation axis and by Weissenberg oscillation photographs ${ }^{9}$.

\section{PATTERSON-HARKER-ANALYSIS}

There are about 250 reflections available for the structure determination. By means of the $/\left.F\right|^{2}$-values from the reflections $h k 0$ and $0 k l$ the Pattersonprojections $p(x y)$ and $p(y z)$ were calculated. In the case of $\mathrm{Mg}_{3}\left(\mathrm{BO}_{3}\right)_{2}$ the result of these calculations is given in the Figs. 1 and 2.

On account of the symmetry elements existing in the space group $D_{2 h^{-}}^{12}$ Pnmn it is advisable to develop the function $p(x y z)$ in the cuts $P(x y 0)$ and $P(x y, 1 / 2)$ to get the sites of the different kind of atoms. In the Figs. 3 and 4 these sections are reproduced in the case of $\mathrm{Mg}_{3}\left(\mathrm{BO}_{3}\right)_{2}$. 


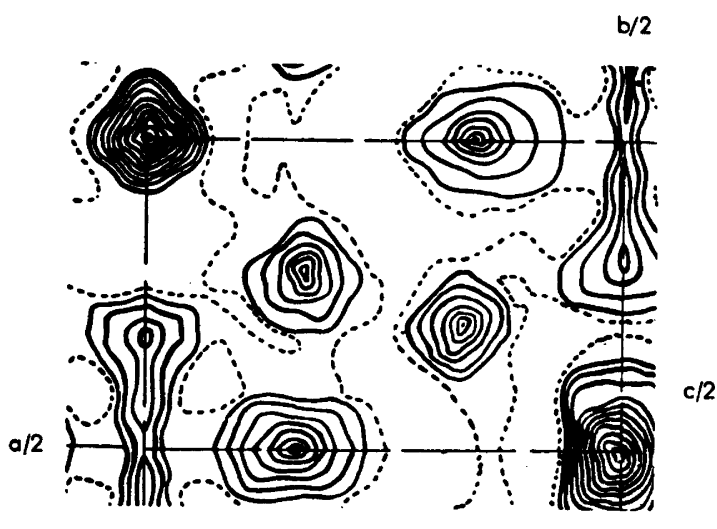

Fig. 1. Projection of the Patterson-function of $\mathrm{Mg}_{3}\left(\mathrm{BO}_{3}\right)_{2}$ on the ab-plane, $p(x y)$. The dotted line corresponds to the O-level.

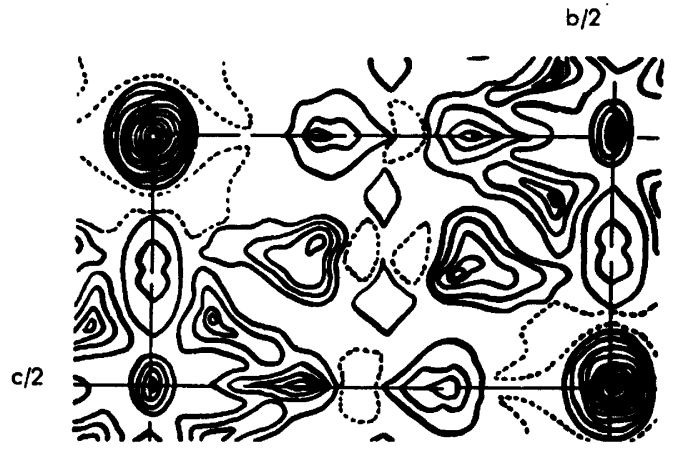

Fig. 2. Projection of the Patterson-function of $\mathrm{Mg}_{3}\left(\mathrm{BO}_{3}\right)_{2}$ on the bc-plane, $p(y z)$.

By combining the different vectors found in the above projections and cuts the atomic arrangement given below will be the only one possible from space reasons. The (4g)-position of the boron-ions is based on the fact that it permits the placing of the boron ions in the centres of gravity of the nearly equilateral triangles formed by the oxygen ions. As will be shown below the dimensions of these triangles are nearly the same as the dimensions of $(\mathrm{BO})_{3^{3-}-}$ triangles, which have been determined in other borates. The denomination is in accordance with the International tables for the determination of crystal structure, Berlin (1935).

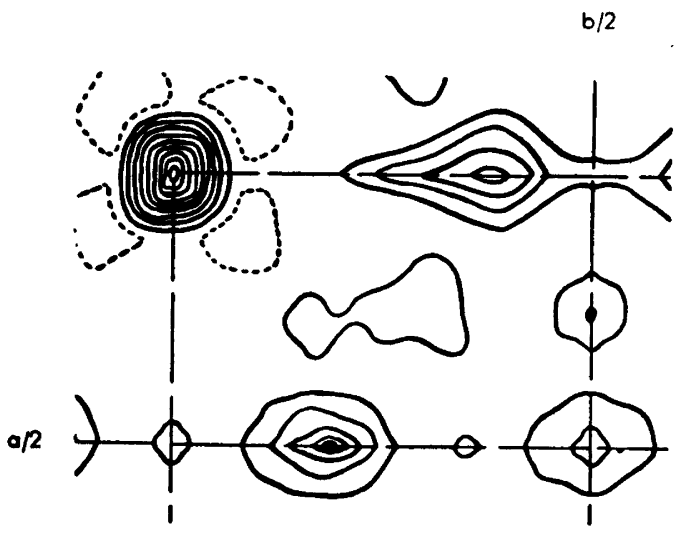

Fig. 3. The Harker-section $P(x y 0)$ of $\mathrm{Mg}_{3}\left(\mathrm{BO}_{3}\right)_{2}$.

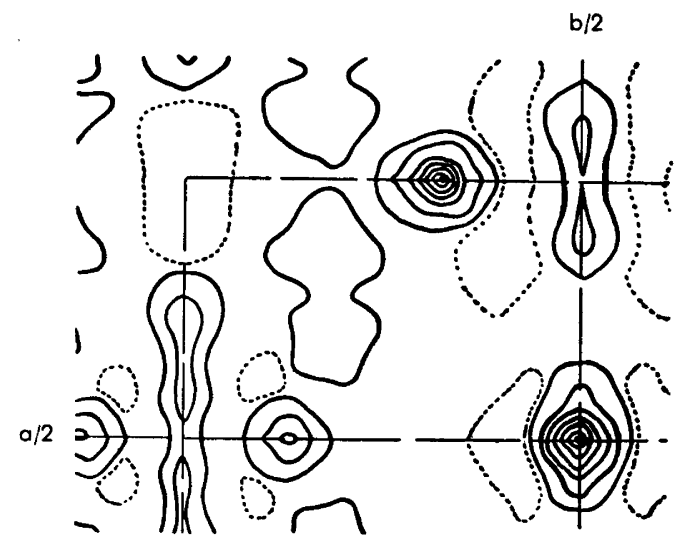

Fig. 4. The Harker-section $P(x y 1 / 2)$ of $\mathrm{Mg}_{3}\left(\mathrm{BO}_{3}\right)_{2}$. 


$$
\begin{array}{lll}
2 & \mathrm{Me}^{2+} \text { in }(2 \mathrm{a})=\mathrm{MeI} \\
4 & \mathrm{Me}^{2+},(4 \mathrm{f})=\mathrm{MeII} \\
4 & \mathrm{~B}^{3+},(4 \mathrm{~g})=\mathrm{B} \\
4 & \mathrm{O}^{2-},(4 \mathrm{~g})=\mathrm{OI} \\
8 & \mathrm{O}^{2-},(8 \mathrm{~h})=\mathrm{OII}
\end{array}
$$

The result of the above calculations are registered in Table 2 pointing out the different maxima arising from the reported vectors. The relative heights of the peaks are assigned to a common scale based on the calculated heights

\begin{tabular}{|c|c|c|c|c|c|c|}
\hline \multicolumn{3}{|c|}{ Coordinates } & \multicolumn{2}{|c|}{ Relative heights } & \multirow{2}{*}{\multicolumn{2}{|c|}{ Interatomic vectors }} \\
\hline$a / 60$ & $\mathrm{~b} / 60$ & $\mathrm{c} / 60$ & $\mathrm{Co}_{3}\left(\mathrm{BO}_{3}\right)_{2}$ & $\mathrm{Mg}_{3}\left(\mathrm{BO}_{3}\right)_{2}$ & & \\
\hline 0 & $\mathbf{0}$ & 0 & 4966 & 1816 & $\begin{array}{r}6 \\
12 \\
4\end{array}$ & $\begin{array}{r}\mathrm{Me}-\mathrm{Me} \\
\mathrm{O}-\mathrm{O} \\
\mathrm{B}-\mathrm{B}\end{array}$ \\
\hline 18 & 0 & 14 & 1250 & 593 & $\begin{array}{l}4 \\
8 \\
4 \\
2 \\
4 \\
4\end{array}$ & $\begin{array}{l}\mathrm{MeI}-\mathrm{OI} \\
\mathrm{MeII}-\mathrm{OII} \\
\mathrm{MeI}-\mathrm{B} \\
\mathrm{OI}-\mathrm{OI} \\
\mathrm{OII}-\mathrm{OII} \\
\mathrm{OI}-\mathrm{B}\end{array}$ \\
\hline 12 & 10 & 14 & 1386 & 655 & $\begin{array}{l}4 \\
4 \\
4 \\
4 \\
4 \\
4 \\
2 \\
4\end{array}$ & $\begin{array}{l}\text { MeI - OII } \\
\text { MeII - OI } \\
\text { MeII - OII } \\
\text { MeII - B } \\
\text { OI - OII } \\
\text { OII - OII } \\
\text { OII - B }\end{array}$ \\
\hline 30 & 10 & 0 & 3420 & 1042 & $\begin{array}{l}4 \\
2 \\
8 \\
4 \\
8\end{array}$ & $\begin{array}{c}\text { MeI - MeII } \\
\text { MeII - MeII } \\
\text { OI - OII } \\
\text { OII - OII } \\
\text { OII - B }\end{array}$ \\
\hline
\end{tabular}
of the maxima in the origin. The coordinates given are not differentiated for the two compounds because of the nearly equal values found. Reference is also made to Fig. 5 .

Table 2. The interatomic vectors of the function $p(x y z)$. 


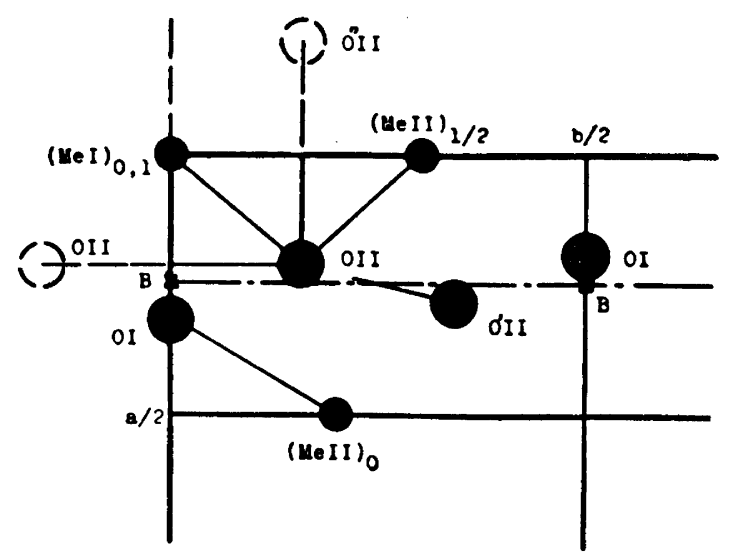

Fig. 5. Projection of the structure parallel to (001). The subscripts correspond to the $z$-coordinates.

The coordinates of the maxima given in Table 2 lead to the following approximate parameters.

$$
\begin{array}{cr}
\text { MeII } & y=0.327 \\
\text { OI } x=0.317 & z=0.273 \\
\text { OII } x=0.202 y=0.139 & z=0.702
\end{array}
$$

Thereby the parameter of the metal-ions is obtained from $\mathrm{Co}_{3}\left(\mathrm{BO}_{3}\right)_{2}$ and the oxygen-parameters from $\mathrm{Mg}_{3}\left(\mathrm{BO}_{3}\right)_{2}$. By means of these parameters the signs necessary for calculating the electron density function are known.

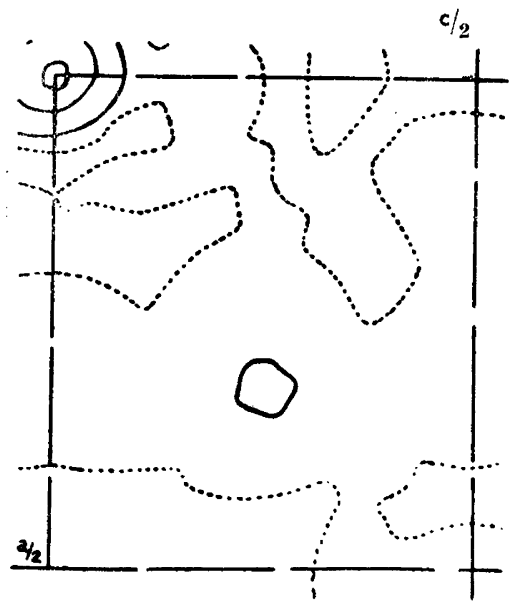

Fig. 6. The section $\varrho(x O z)$ of the electron density of $\mathrm{Mg}_{3}\left(\mathrm{BO}_{3}\right)_{2}$. The height difference $=100$. The dotted line $=0$-level. 


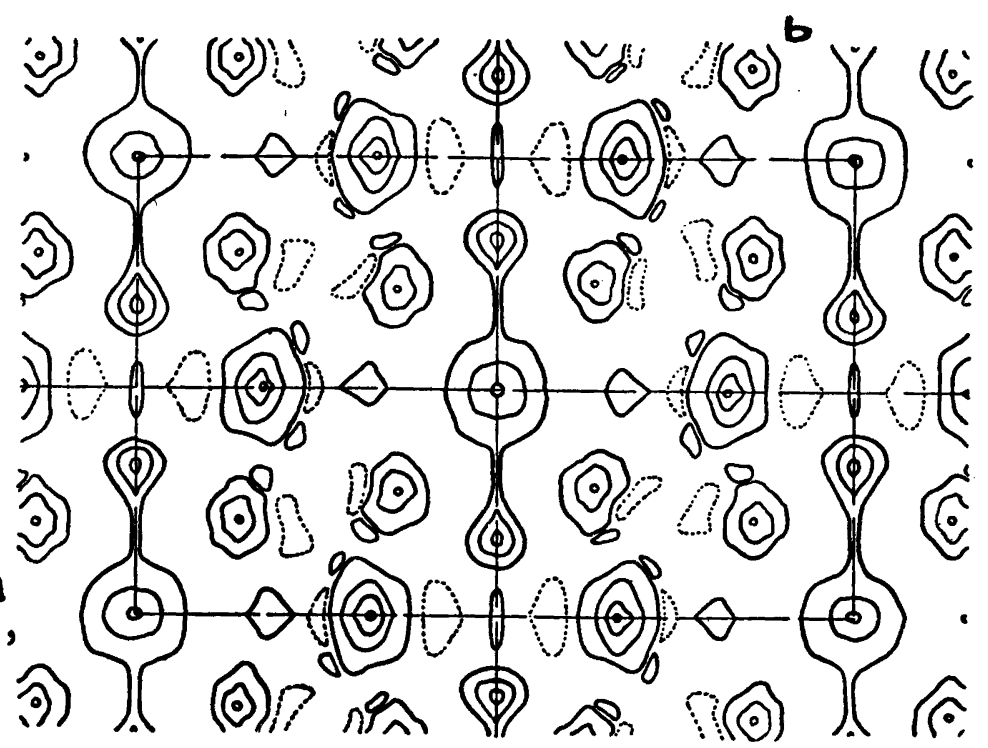

Fig. 7. $\mathrm{Mg}_{3}\left(\mathrm{BO}_{3}\right)_{2}$. Projection of the electron density parallel to [001]. The height-difference $=10$.

The dotted line $=-10$-level .

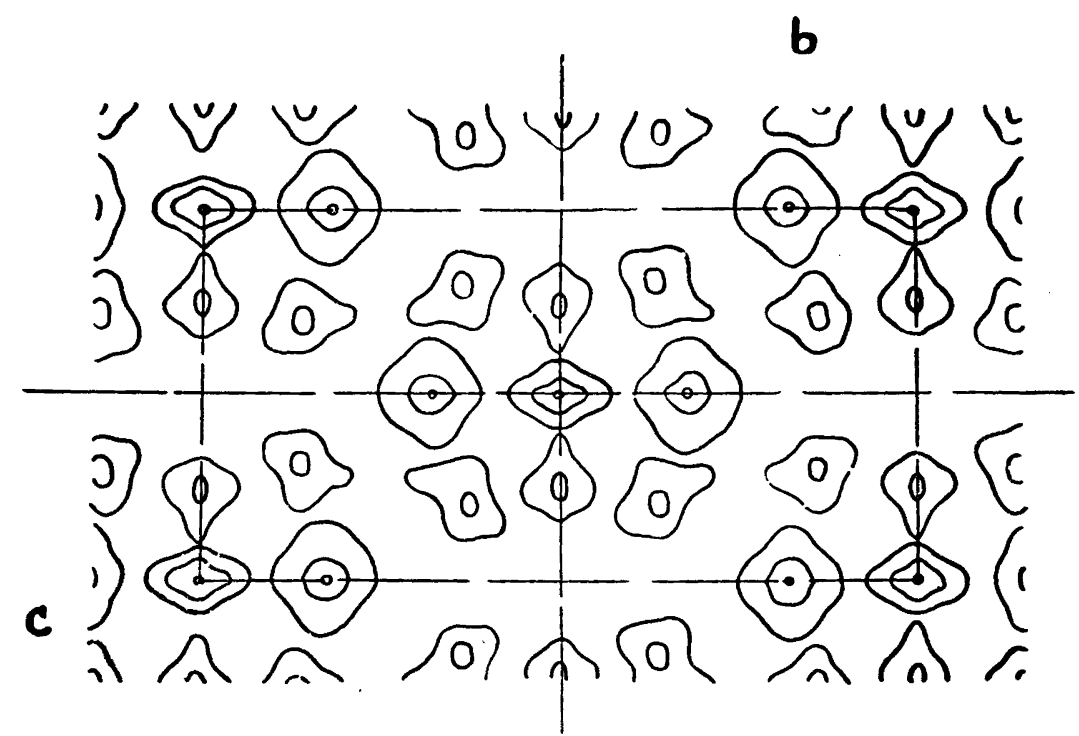

Fig. 8. $\mathrm{Mg}_{3}\left(\mathrm{BO}_{3}\right)_{2}$. Projection of the electron density parallel to [100]. 


\section{DETERMINATION OF THE FINAL PARAMETERS}

The practically equal coordinate values for the Patterson maxima of $\mathrm{Co}_{3}\left(\mathrm{BO}_{3}\right)_{2}$ and $\mathrm{Mg}_{3}\left(\mathrm{BO}_{3}\right)_{2}$ respectively, together with the fact that the ionic radii of $\mathrm{Co}^{2+}$ and $\mathrm{Mg}^{2+}$ are nearly the same - which is also evident from the close agreement between unit dimensions and axial ratios of the two compounds - makes it highly probable that the parameter values of the two cells are nearly equal. Thus, the approximate parameter values, derived from the Patterson syntheses, have been used for determining the signs of the F-values in calculating the electron density. For both compounds the electron density was calculated in the section $\varrho(x 0 z)$ and the projections $\varrho(x y)$ and $\varrho(y z)$. The results are shown for $\mathrm{Mg}_{3}\left(\mathrm{BO}_{3}\right)_{2}$ in the Figs. 6-8. The final parameter values are given below and proved to be identical for the two compounds. The boron values have been calculated on the asumption that the boron ions occupy the centres of gravity of the practically equilateral oxygen triangles.

The structure of $\mathrm{Co}_{3}\left(\mathrm{BO}_{3}\right)_{2}$ and $\mathrm{Mg}_{3}\left(\mathrm{BO}_{3}\right)_{2}$ in $D_{2 h}^{12}-P n m n$ will then be characterized by the positions

$$
\begin{aligned}
& 2 \mathrm{Me}^{2+} \text { in }(2 \mathrm{a})=\mathrm{MeI} \\
& 4 \mathrm{Me}^{2+} \text { in }(4 \mathrm{f})=\mathrm{MeII} \quad y=0.321 \\
& 4 \mathrm{~B}^{3+} \text { in }(4 \mathrm{~g})=\mathrm{B} \quad x=0.25 \quad z=0.56 \\
& 4 \mathrm{O}^{2-} \text { in }(4 \mathrm{~g})=\mathrm{OI} \quad x=0.316 \quad z=0.258 \\
& 8 \mathrm{O}^{2-} \text { in }(8 \mathrm{~h})=\mathrm{OII} \quad x=0.218 y=0.139 z=0.705
\end{aligned}
$$

\section{DISCUSSION OF THE STRUCTURE}

The structure in question is projected in the Figures 9 and 10.

$\left(\mathrm{BO}_{3}\right)^{3-}$-triangle. The most characteristic feature of the atomictarrangement is formed by the rather equilateral $\left(\mathrm{BO}_{3}\right)^{3-}$-triangles, with their very short co-planar bonds found to be

\begin{tabular}{lll}
\hline & $\mathrm{Co}_{3}\left(\mathrm{BO}_{3}\right)_{2}$ & $\mathrm{Mg}_{3}\left(\mathrm{BO}_{3}\right)_{2}$ \\
\hline OI - OII & $2.399 \AA$ & $2.383 \AA$ \\
OII - OII & 2.346 & 2.339 \\
B - OI & 1.44 & 1.42 \\
B - OII & 1.35 & 1.34
\end{tabular}

Analogous distances within $\left(\mathrm{BO}_{3}\right)^{3-}$-triangles have been proved by 


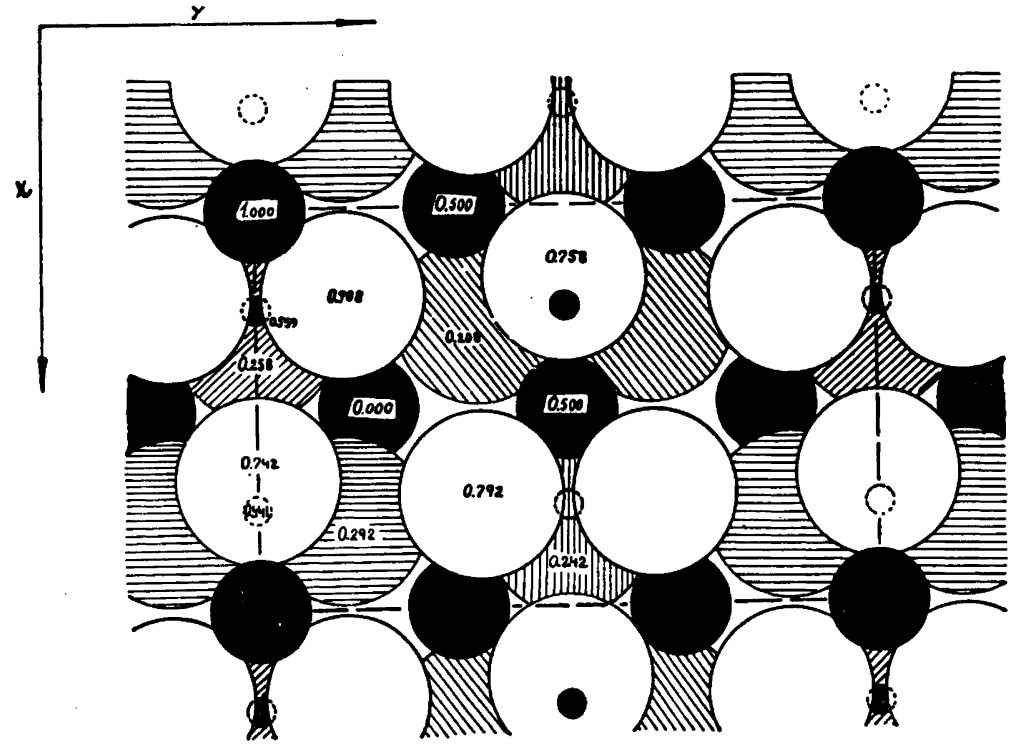

Fig. 9. Projection of the structure parallel to [001].

The large black spheres represent the metal-ions,

" small " " boron- "

" large white ",$~ o x y g e n-"$

Equal heights over the planes in question are similarely marked, and the heights over the base-plane are given by numbers within the spheres in the cell.

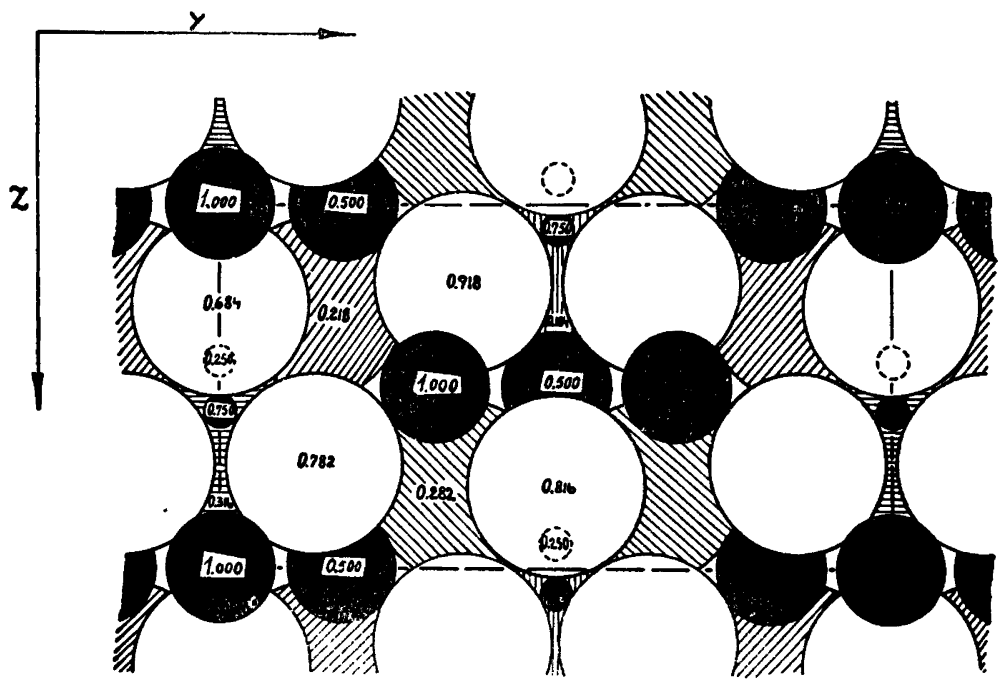

Fig. 10. Projection of the structure parallel to [100]. 


\begin{tabular}{clll} 
Author & Substance & $\begin{array}{c}\text { Oxygen-oxygen- } \\
\text { distances }\end{array}$ & $\begin{array}{c}\text { Boron-oxygen- } \\
\text { distances }\end{array}$ \\
\hline $\begin{array}{l}\text { Zachariasen } \\
\text { Zachariasen } \\
\quad \text { Ziegler }\end{array}$ & Hambergite & $2.31-2.35-2.39 \AA$ & $1.42-1.35-1.28 \AA$ \\
Fang ${ }^{13}$ & $\mathrm{CaB}_{2} \mathrm{O}_{4}$ & $2.35-2.36-2.37$ & $1.38-1.37-1.34$ \\
& $\mathrm{NaB}_{2} \mathrm{O}_{4}$ & $2.32-2.37$ & $1.34-1.38$
\end{tabular}

Wells ${ }^{14}$ reports the boron-oxygen distance within the triangles to be $1.35 \AA$. As will be seen from the projection of the structure on the $a b$-plane Fig. 9 - the oxygen-ions form layers including the $\left(\mathrm{BO}_{3}\right)^{3-}$-triangles, with the boron-ions situated in the $n$-planes at right angles to the $x$-axis.

$\left(\mathrm{MeO}_{6}\right)^{10-}$-octahedron. Moreover, it is obvious from the Figs. 9 and 10 that the metal-ions connecting the layers have the coordination number six. Within the octahedrons formed, the following interionic distances are found

\begin{tabular}{lll}
\hline & $\mathrm{Co}_{3}\left(\mathrm{BO}_{3}\right)_{2}$ & $\mathrm{Mg}_{3}\left(\mathrm{BO}_{3}\right)_{2}$ \\
\hline$(\mathrm{MeI})_{1}-$ OII & $2.141 \AA$ & $2.108 \AA$ \\
$(\mathrm{MeI})_{0}-$ OI & 2.086 & 2.063 \\
$(\mathrm{MeII})_{0}-$ OI & 2.157 & 2.146 \\
$(\mathrm{MeII})_{1 / 2}-$ OII & 2.152 & 2.164
\end{tabular}

The remaining interionic distances in the structure are
OII $\quad-\mathrm{O}^{\prime} \mathrm{II}$
$2.958 \AA$
$2.945 \AA$
OII $\quad-\mathrm{O}^{\prime \prime} \mathrm{II}$
3.020
2.988

These distances show that the binding within the $\left(\mathrm{BO}_{3}\right)^{3-}$-triangles undoubtedly are much stronger than the other bonds. There is, in other words direct evidence for the existance of $\left(\mathrm{BO}_{3}\right)^{3-}$-groups in the structure. Accordingly the chemical formula of the compounds under investigation must be written as $\mathrm{Me}_{3}\left(\mathrm{BO}_{3}\right)_{2}$.

By using the above parameters and atomic scattering factors according to the International tables for the determination of crystal structure (Berlin, 1935), the following agreement between calculated and observed F-values was obtained: 
Ok0.reflections

\begin{tabular}{|c|c|c|c|c|}
\hline \multirow[b]{2}{*}{$h l k l$} & \multicolumn{2}{|c|}{$\mathrm{Co}_{3}\left(\mathrm{BO}_{3}\right)_{2}$} & \multicolumn{2}{|c|}{$\mathrm{Mg}_{3}\left(\mathrm{BO}_{3}\right)_{2}$} \\
\hline & $\mid F /$ obs & $F_{\text {calc. }}$ & $|F|_{\text {obs }}$ & $\boldsymbol{F}_{\text {calc. }}$ \\
\hline 020 & 15.8 & 10.1 & 23.0 & 13.9 \\
\hline 040 & 10.1 & 2.5 & 5.5 & $-\quad 7.6$ \\
\hline 060 & 110.0 & 108.7 & 59.5 & 61.7 \\
\hline 080 & - & 2.0 & 18.8 & 13.8 \\
\hline 0100 & 20.3 & 28.8 & 12.6 & 7.8 \\
\hline 0120 & 16.3 & 39.2 & 10.9 & 14.3 \\
\hline 0140 & - & 0.6 & 6.1 & 11.8 \\
\hline 0160 & 15.9 & 40.7 & 9.1 & 17.0 \\
\hline \multicolumn{5}{|c|}{ hk0-reflections } \\
\hline 110 & - & 1.7 & - & -1.5 \\
\hline 130 & 114.7 & 98.3 & 36.7 & $\mathbf{3 4 . 0}$ \\
\hline 150 & 34.8 & -27.4 & 20.1 & -16.1 \\
\hline 170 & 33.9 & 28.0 & 16.2 & 11.8 \\
\hline 190 & 42.2 & 54.8 & 16.8 & 18.9 \\
\hline 1110 & 12.7 & -24.3 & 7.3 & -11.8 \\
\hline 1130 & 20.2 & 30.8 & 1.9 & 8.8 \\
\hline 200 & 62.8 & 62.6 & 16.5 & -6.6 \\
\hline 220 & 28.5 & -17.4 & 20.1 & -11.4 \\
\hline 240 & 42.3 & 35.4 & 24.0 & 23.8 \\
\hline 260 & 53.3 & 62.0 & 10.5 & 21.7 \\
\hline 280 & 40.5 & -36.7 & 31.1 & -24.8 \\
\hline 2100 & 38.8 & 35.7 & 14.7 & 16.3 \\
\hline 2120 & 32.2 & 41.5 & 2.9 & 15.4 \\
\hline 2140 & 8.1 & -28.9 & 10.1 & -18.7 \\
\hline 310 & - & 7.9 & - & -5.5 \\
\hline 330 & 115.2 & 121.4 & 64.1 & 64.1 \\
\hline 350 & 6.2 & $-\quad 1.4$ & 9.2 & 7.4 \\
\hline 370 & 33.1 & 23.6 & 12.6 & 8.5 \\
\hline 390 & 52.8 & 59.8 & 26.3 & 26.6 \\
\hline 3110 & 5.1 & -4.1 & 2.7 & 7.2 \\
\hline 3130 & 21.2 & 34.4 & 6.8 & 12.7 \\
\hline 400 & 104.8 & 103.1 & 54.9 & 52.7 \\
\hline 420 & 10.1 & -11.5 & - & -6.8 \\
\hline 440 & 1.0 & 1.7 & 5.5 & -7.3 \\
\hline 460 & 65.1 & 70.7 & 35.7 & 30.0 \\
\hline 480 & 8.4 & -10.5 & - & 0.8 \\
\hline 4100 & 13.0 & 20.6 & - & 1.8 \\
\hline
\end{tabular}




\begin{tabular}{|c|c|c|c|c|}
\hline \multicolumn{3}{|c|}{$\mathrm{Co}_{3}\left(\mathrm{BO}_{3}\right)_{2}$} & \multicolumn{2}{|c|}{$\mathrm{Mg}_{3}\left(\mathrm{BO}_{3}\right)_{2}$} \\
\hline$h k l$ & $\mid F /$ obs & $F_{\text {calc }}$ & $|F|$ obs & $F_{\text {calc }}$ \\
\hline 510 & - & 5.9 & - & 3.3 \\
\hline 530 & 47.7 & 52.7 & vw & 8.1 \\
\hline 550 & 10.9 & -24.7 & 19.4 & -16.0 \\
\hline 570 & 26.6 & 27.2 & 17.0 & 13.2 \\
\hline 590 & 31.7 & 41.9 & vw & 9.7 \\
\hline 5110 & 12.0 & -31.0 & 16.9 & -20.2 \\
\hline 600 & 56.1 & 69.3 & 35.4 & 25.5 \\
\hline 620 & - & $-\quad 0.4$ & - & 4.8 \\
\hline 640 & 16.3 & 25.8 & 4.1 & 14.8 \\
\hline 660 & 48.5 & 58.4 & 25.2 & 21.7 \\
\hline 710 & - & $-\quad \mathbf{5 . 0}$ & - & $-\quad 5.9$ \\
\hline 730 & 61.0 & 69.5 & 32.1 & 31.9 \\
\hline 750 & - & $-\quad 5.1$ & - & 2.3 \\
\hline 770 & 7.2 & 7.1 & vw & -4.6 \\
\hline 800 & 37.2 & 46.3 & 9.2 & 11.8 \\
\hline 820 & vw & -10.4 & vw & $-\quad 7.5$ \\
\hline 840 & 8.3 & 14.4 & - & $-\quad 2.4$ \\
\hline 860 & 33.8 & 39.3 & - & 2.6 \\
\hline 910 & vw & 13.3 & 3.3 & 11.2 \\
\hline 930 & 31.8 & 40.5 & 2.7 & 7.2 \\
\hline 950 & 11.2 & -9.0 & - & -3.2 \\
\hline \multirow[t]{2}{*}{1000} & 22.1 & 51.1 & 14.2 & 20.8 \\
\hline & & okl-reflections & & \\
\hline 002 & 44.8 & 59.4 & vw & $-\quad 5.4$ \\
\hline 004 & 78.4 & 97.2 & 42.5 & 51.0 \\
\hline 006 & 40.8 & 52.6 & 5.7 & 13.9 \\
\hline 008 & 35.3 & 44.4 & vw & 12.9 \\
\hline 022 & 28.0 & -21.6 & 16.5 & -16.3 \\
\hline 024 & - & 3.7 & 2.9 & 7.7 \\
\hline 026 & vw & -10.6 & 5.8 & -7.3 \\
\hline 031 & 34.6 & -28.9 & 17.4 & -7.8 \\
\hline 033 & 55.0 & -40.7 & 33.0 & -24.5 \\
\hline 035 & 12.6 & -10.1 & - & 2.9 \\
\hline
\end{tabular}


Okl-reflections

\begin{tabular}{|c|c|c|c|c|}
\hline \multirow[b]{2}{*}{$h k l$} & \multicolumn{2}{|c|}{$\mathrm{Co}_{3}\left(\mathrm{BO}_{3}\right)_{2}$} & \multicolumn{2}{|c|}{$\mathrm{Mg}_{3}\left(\mathrm{BO}_{3}\right)_{2}$} \\
\hline & $\mid F /$ obs & $F_{\text {calc. }}$ & $|F|_{\text {obs }}$ & $F_{\text {calc. }}$ \\
\hline 042 & 49.4 & 27.7 & 25.9 & 16.7 \\
\hline 044 & 23.0 & 14.3 & 18.8 & 5.6 \\
\hline 046 & vw & 7.0 & 4.6 & -0.3 \\
\hline 051 & 76.3 & 85.3 & 38.0 & 38.1 \\
\hline 053 & 61.5 & 64.5 & 26.6 & 24.8 \\
\hline 055 & 51.5 & 55.4 & 19.4 & 21.4 \\
\hline 062 & 53.4 & 57.6 & 13.7 & 12.8 \\
\hline 064 & 64.5 & 72.6 & 35.2 & 34.0 \\
\hline 066 & 22.3 & 42.9 & 10.1 & 9.9 \\
\hline 071 & 15.9 & 20.0 & - & 5.1 \\
\hline 073 & 24.1 & 34.9 & 10.3 & 21.1 \\
\hline 075 & - & 4.1 & vw & -4.9 \\
\hline 082 & 39.3 & -37.5 & 26.6 & -26.0 \\
\hline 084 & vw & -4.3 & - & 6.2 \\
\hline 091 & 10.9 & -12.6 & vw & -5.1 \\
\hline 0102 & 38.3 & 32.7 & 19.2 & 13.2 \\
\hline 0104 & 21.5 & 27.7 & 5.2 & 9.9 \\
\hline \multirow[t]{2}{*}{0111} & 31.3 & 60.4 & 10.1 & 23.1 \\
\hline & & hol-reflections & & \\
\hline 101 & 38.5 & -44.7 & 17.1 & -21.0 \\
\hline 102 & 26.5 & -17.1 & 16.8 & -17.1 \\
\hline 103 & 26.5 & -28.1 & 9.4 & -10.6 \\
\hline 104 & - & 13.9 & 9.4 & 13.9 \\
\hline 105 & 8.7 & -24.4 & 5.5 & -10.5 \\
\hline 201 & 28.0 & 32.9 & 39.9 & 32.9 \\
\hline 202 & 112.0 & 136.7 & 65.9 & 70.0 \\
\hline 203 & 19.4 & -14.6 & 21.6 & -14.6 \\
\hline 204 & 56.2 & 65.2 & 25.3 & 20.6 \\
\hline 205 . & - & 6.6 & 5.5 & 6.6 \\
\hline 206 & 26.4 & 60.5 & 25.8 & 23.0 \\
\hline
\end{tabular}




\begin{tabular}{|c|c|c|c|c|}
\hline \multirow[b]{2}{*}{$h k l$} & \multicolumn{2}{|c|}{$\mathrm{Co}_{3}\left(\mathrm{BO}_{3}\right)_{2}$} & \multicolumn{2}{|c|}{$\mathrm{Mg}_{3}\left(\mathrm{BO}_{3}\right)_{2}$} \\
\hline & $\mid F /$ obs & $F_{\text {cala. }}$ & $\mid F /$ obs & $F_{\text {calc. }}$ \\
\hline 301 & 27.2 & -30.0 & 13.3 & -18.0 \\
\hline 302 & vw & 9.7 & 12.2 & 9.7 \\
\hline 303 & 38.1 & -33.2 & 27.8 & -17.4 \\
\hline 304 & - & -11.0 & vw & -11.0 \\
\hline 305 & vw & -14.4 & - & $-\quad 1.2$ \\
\hline 306 & - & 9.6 & 12.5 & 9.6 \\
\hline 401 & 27.5 & -26.4 & 35.5 & -26.4 \\
\hline 402 & 59.2 & 70.3 & 27.4 & 22.3 \\
\hline 403 & 19.8 & 16.7 & 14.6 & 16.7 \\
\hline 404 & 62.1 & 69.7 & 33.7 & 28.3 \\
\hline 405 & - & -8.6 & - & -8.6 \\
\hline 406 & 30.1 & 52.2 & 26.2 & 16.8 \\
\hline 501 & 22.5 & -24.8 & 19.5 & -9.5 \\
\hline 502 & - & -4.8 & - & $-\quad 4.8$ \\
\hline 503 & vw & -14.1 & - & $-\quad 0.3$ \\
\hline 504 & - & 7.0 & $\mathbf{v w}$ & 7.0 \\
\hline 505 & 12.7 & -27.0 & 14.3 & -14.8 \\
\hline 601 & 10.9 & 18.5 & 25.1 & 18.5 \\
\hline 602 & 51.0 & 55.3 & 8.3 & 13.9 \\
\hline 603 & - & -13.1 & 5.1 & -13.1 \\
\hline 604 & 50.1 & 57.8 & 21.4 & 20.6 \\
\hline 701 & $v w$ & -16.4 & - & $-\quad 3.4$ \\
\hline 702 & - & 1.1 & - & 1.1 \\
\hline 801 & - & -10.5 & 3.4 & -10.5 \\
\hline 802 & 50.7 & 57.3 & 22.9 & 22.2 \\
\hline
\end{tabular}

The crystal structure of the isomorphous orthoborates of cobalt and magnesium is found to be orthorhombic with $2 \mathrm{Me}_{3}\left(\mathrm{BO}_{3}\right)_{2}$ in the unit cell. The dimensions of the orthorhombic unit are determined. From the interatomic bond lengths found, it is clear that the most characteristic part of the structure is the nearly equilateral $\left(\mathrm{BO}_{3}\right)^{3-}$-triangles and that in consequence of this the formula must be written as $\mathrm{Me}_{3}\left(\mathrm{BO}_{3}\right)_{2}$. The oxygen lattice forms layers parallell to [100] including the triangles and connected by the metal ions with coordination number six. The parameters have been determined by means of Fourier-methods. 
The present study was carried out at the Institute of Inorganic Chemistry of the University of Uppsala. To the Head of this Institute Professor G. Hägg, who has not only suggested the problem but even stimulated the interest by many discussions and helpful criticism, I wish to express my sincere gratitude.

My best thanks are also due to his co-workers, especially Dr. A. Magnéli, for many valuable conversations.

To the Head of the Institute of Silicate Research at Chalmers Techn. Univ. Professor J. Arvid Hedvall I wish to form my special gratitude for the kind interest he always has devoted to my work.

After having finished the present study a copy of a japanese paper by R. Sadanaga ${ }^{15}$ 'The crystal structure of Kotoite, $\mathrm{Mg}_{3} \mathrm{~B}_{2} \mathrm{O}_{6}$ ' - up to this day not yet reported in literature - has been received in this Institute.

This structure determination which is based on the asumption of a structural analogy between $\mathrm{Mg}_{2} \mathrm{SiO}_{4}$ and $\mathrm{Mg}_{3} \mathrm{~B}_{2} \mathrm{O}_{6}$ and performed by means of trial and error methods, has resulted in a structure, which is practically identical with the above. The parameter values show slight differences but the present author is of the opinion that his values, derived by Fourier-methods, give a slightly better agreement between observed and calculated intensities. It is also worth mentioning that the dimensions of the $\left(\mathrm{BO}_{3}\right)^{3^{-}}$-triangles obtained with Sadanaga's values do not agree very well with those reported by earlier authors.

\section{REFERENCES}

1. Ebelmen, J. J. Ann. chim. et phys. (3) 33 (1851) 50.

2. Mallard, E. Compt. rend. 105 (1887) 1263, Ann. mines. (8) 12 (1887) 439.

3. Ie Chatelier, H. Compt. rend. 113 (1891) 1034.

4. Ouvrard, L. Compt. rend. 132 (1901) 257.

5. Guertler, W. Z. anorg. Ch. 40 (1904) 225.

6. Hofmann, K. A. and Höschele, K. Ber. 47 (1914) 239.

7. The calculations of the twodimensional Fourier-series were carried out with the aid of the electric calculating machine, constructed by G. Hägg and T. Laurent ( J. Sci. Instruments 23 (1946) 155).

8. Lu, C. S. Rev. Sci. Instruments 14 (1943) 331.

9. Magnéli, A. Acta chem. Scand. 2 (1948) 501.

10. Intern. tables for the det. of crystal structures, Berlin (1935).

11. Zachariasen, W. E. Z. Krist. 76 (1931) 289.

12. Zachariasen, W. H. and Ziegler, G. E. Z. Krist. 83 (1932) 354.

13. Fang, S. M. Z. Krist. 99 (1938) 1.

14. A. F. Wells: $J$. Chem. Soc. London (1949) 55.

15. Sadanga, R. X-Rays. Vol. 5 No. $1-2$ (1948) 2. 